\title{
CORRELATIONS BETWEEN THE ROLLING TEXTURES IN FCC Ni-Co ALLOYS AND THE BCC TRANSFORMATION TEXTURES IN CONTROLLED ROLLED STEELS
}

\author{
R. K. RAY, $\dagger$ PH. CHAPELLIER and J. J. JONAS \\ Department of Metallurgical Engineering, McGill University, 3450 University St., \\ Montreal, Quebec H3A 2 A7 Canada
}

(Received March 3 1989)

\begin{abstract}
Three fcc Ni-Co alloys with different stacking fault energies (SFE's) were cold rolled $95 \%$ and their textures were characterized by the orientation distribution function (ODF) method. BCC transformation textures were calculated from these experimental textures using three different orientation relationships for the $\gamma \rightarrow \alpha$ transformation. The transformed ODF's derived from the Bain relationship were much sharper than the ones deduced from the Kurdjumov-Sachs (K-S) or the Nishiyama-Wassermann $(\mathrm{N}-\mathrm{W})$ relations. The ferrite texture determined on a controlled rolled steel, heavily deformed in the unrecrystallized $\gamma$ region, agrees reasonably well with the bcc texture calculated using the $\mathrm{K}-\mathrm{S}$ relation from the rolled $\mathrm{Ni}-\mathrm{Co}$ alloy with similar SFE. The major texture components of the ferrite, namely $\{332\}\langle 113\rangle$ and $\{311\}\langle 011\rangle$, are found to originate from the two major rolling texture components of the austenite, i.e. the $\{110\}\langle 112\rangle(\mathrm{Bs})$ and $\{112\}\langle 111\rangle(\mathrm{Cu})$, respectively. Such ferrite transformation from heavily deformed austenite seems to follow the $\mathrm{K}-\mathrm{S}$ relationship without any variant selection. By contrast, the texture of the martensite produced from deformed austenite appears to involve significant amounts of variant selection.
\end{abstract}

KEY WORDS Rolling textures, oriented phase transformation, variant selection, stacking fault energy, nickel-cobalt alloys

\section{INTRODUCTION}

During controlled rolling, steels are normally subjected to repeated reductions in the unrecrystallized austenite $(\gamma)$ phase. As a result, the $\gamma$ accumulates considerable strain, leading to the development of fairly sharp rolling textures. Experimental difficulties often preclude the determination of this texture in commercial steels, which undergo phase transformation during cooling to room temperature. Nevertheless, because of the existence of orientation relationships between parent and product phases, it is possible to infer the parent texture from the preferred orientations of the product phase, and vice versa. In the case of steels, three such orientation relationships have so far been proposed between austenite and transformed ferrite $(\alpha)$ or martensite $\left(\alpha^{\prime}\right)$ (Bain 1924, Kurdjumov and Sachs 1930, Nishiyama 1934, Wassermann 1933). These are described in Table 1.

$\dagger$ On sabbatical leave from the Department of Metallurgical Engineering, Indian Institute of Technology, Kanpur 208016 (India). 
Table 1 Orientation relationships between $\gamma$ and $\alpha$ or $\alpha^{\prime}$

\begin{tabular}{llll}
\hline $\begin{array}{l}\text { Orientation } \\
\text { relationship }\end{array}$ & $\begin{array}{l}\text { Lattice correspondence } \\
\text { relation }\end{array}$ & $\begin{array}{l}\text { Number of } \\
\text { alternatives }\end{array}$ & $\begin{array}{l}\text { Total } \\
\text { number of } \\
\text { variants }\end{array}$ \\
\hline Bain (B) & $\{001\}_{\gamma} / /\{001\}_{\alpha}$ & 3 & 3 \\
Kurdjumov- & $\left.\langle 100\rangle_{\gamma} / / 110\right\rangle_{\alpha}$ & 1 & \\
Sachs (K-S) & $\left.\{111\}_{\gamma} / / 011\right\rangle_{\alpha}$ & 4 & 24 \\
Nishiyama- & $\langle 011\rangle_{\gamma} /\langle 111\rangle_{\alpha}$ & 3 & \\
Wassermann (N-W) & $\{111\}_{\gamma} / /\{011\}_{\alpha}$ & 4 & 12 \\
\hline
\end{tabular}

In fcc metals and alloys, it is usual to distinguish between three different types of cold rolling texture: (i) the brass or alloy type in low stacking fault energy (SFE) materials, (ii) the copper or pure metal type in medium SFE materials, and (iii) the aluminum type in very high SFE materials. While the brass type consists essentially of the brass component $\operatorname{Bs}\{110\}\langle 112\rangle$, in the copper type, the $\mathrm{Cu}\{112\}\langle 111\rangle, \mathrm{S}\{123\}\langle 634\rangle$ and $\mathrm{Bs}$ components are nearly equally strong, while the $S$ component seems to predominate in the aluminum type (Lücke, 1981). The $\gamma$ rolling texture is generally assumed to be similar to the copper or aluminum textures (Kallend and Davies, 1972; Hu and Kallend, 1981).

The stacking fault energy of $\gamma$-iron is $\sim 75 \mathrm{~mJ} / \mathrm{m}^{2}$ (Charnock and Nutting, 1967). Accordingly, if austenite rolling textures are to be simulated, the experiments should be carried out on fcc materials of comparable SFE. However, the SFE of $\mathrm{Cu}$ is only about $55 \mathrm{~mJ} / \mathrm{m}^{2}$, whereas that of $\mathrm{Al}$ is $200 \mathrm{~mJ} / \mathrm{m}^{2}$ (Gallagher, 1970). An alternative is to make use of alloys based on nickel, for which the SFE is $\sim 130 \mathrm{~mJ} / \mathrm{m}^{2}$ (Haasen, 1978). The addition of cobalt to nickel decreases the SFE, so that an alloy with 30 weight per cent of cobalt is expected to have a stacking fault energy of $\sim 72 \mathrm{~mJ} / \mathrm{m}^{2}$ (Haasen, 1978; Beeston and France, 1968), which is similar to that of $\gamma$-iron.

The present paper concerns the experimental determination of the cold rolling textures of three fcc nickel-cobalt alloys containing nominally 30,40 and 60 weight per cent cobalt. Using crystallite orientation distribution functions or ODF's, the experimental textures are transformed into their bcc equivalents according to the Bain, $\mathrm{K}-\mathrm{S}$ and $\mathrm{N}-\mathrm{W}$ orientation relationships. Finally, the analytically predicted textures are compared with experimental textures for ferrite and martensite in various steels.

\section{EXPERIMENTAL MATERIALS AND METHOD}

The chemical compositions of the Ni-Co alloys employed in the present study are given in Table 2 . The alloys were melted under vacuum and segregation was avoided by magnetic stirring during melting. The ingots were cold rolled 50 per cent to a thickness of $10 \mathrm{~mm}$ and then homogenization annealed in vacuum at $1150^{\circ} \mathrm{C}$ for 24 hours. They were again cold rolled 50 per cent and annealed at 
Table 2 Chemical composition of alloys (weight per cent)

\begin{tabular}{llllllll}
\hline $\begin{array}{l}\text { Alloy } \\
\text { designation }\end{array}$ & \multicolumn{8}{c}{ Alloying element } \\
\cline { 2 - 8 } & $\mathrm{Co}$ & $\mathrm{C}$ & $\mathrm{S}$ & $\mathrm{Si}$ & $\mathrm{Cu}$ & $\mathrm{O}$ & $\mathrm{Ni}$ \\
\hline $\mathrm{Ni} 30 \mathrm{Co}$ & 30.90 & 0.006 & 0.003 & 0.03 & 0.03 & 0.009 & balance \\
$\mathrm{Ni} 40 \mathrm{Co}$ & 41.05 & 0.006 & 0.004 & 0.03 & 0.03 & 0.004 & balance \\
$\mathrm{Ni} 60 \mathrm{Co}$ & 60.50 & 0.006 & 0.004 & 0.06 & 0.03 & 0.007 & balance \\
\hline
\end{tabular}

$1100^{\circ} \mathrm{C}$ for 3 hours to yield starting materials of almost random texture with a grain size of $\sim 0.1 \mathrm{~mm}$.

Final preparation consisted of cold rolling to 95 per cent reduction, using a laboratory mill with $250 \mathrm{~mm}$ diameter rolls. Reproducible textures were found over almost the whole thickness of the sheets, except for narrow zones near the outermost surface.

Material was etched from one side of each sheet to the mid-thickness, at which the texture measurements were carried out. For each sample $(24 \mathrm{~mm} \times 14 \mathrm{~mm})$, the texture was determined by plotting conventional pole figures as well as ODF's. For the latter purpose, four incomplete pole figures, namely the $\{111\}$, $\{200\},\{220\}$ and $\{311\}$, were measured up to an azimuth of $85^{\circ}$. From these data, the ODF's were calculated following the series expansion method of Bunge (1969) and using a computer program designed by Jura and Pospiech (1978).

It is assumed here that these ODF's correspond to the rolling textures of austenites with comparable stacking fault energies. They were then transformed according to the Bain, $\mathrm{K}-\mathrm{S}$ and $\mathrm{N}-\mathrm{W}$ relationships to yield textures corresponding to the bcc $\alpha$ obtained from fcc $\gamma$ by phase transformation (Chapellier 1989). Orientation transformation functions were employed to calculate the product textures from continuous distributions of the parent orientations (Bunge et al., 1984). Equal weights were given to all variants of the tranformation being simulated.

\section{EXPERIMENTAL RESULTS}

The $\Phi_{2}$ sections of the experimental ODF determined on the cold rolled Ni-30 Co alloy are presented in Figure 1a. The $\Phi_{1}$ sections of the ODF's obtained by transforming Figure 1a according to the Bain, $\mathrm{K}-\mathrm{S}$ and $\mathrm{N}-\mathrm{W}$ relationships are shown in Figures $1 \mathrm{~b}$ to $1 \mathrm{~d}$, respectively. (It is usual to represent the textures of fcc materials by $\Phi_{2}$ sections and those of bcc materials by $\Phi_{1}$ sections since most of the important orientations lie in these sections, respectively). Although the general features of the three transformed ODF's are similar, the one deduced from the Bain relationship is much sharper than those calculated from the other two. The N-W ODF is detectably more intense than the K-S ODF, in keeping with the number of variants produced from each starting orientation according to the three relationships, see Table 1 . It is of interest that the $\mathrm{K}-\mathrm{S}$ and $\mathrm{N}-\mathrm{W}$ ODF's are nearly identical, as the two relations involve the same parallelism between planes and there is a difference of only $5.3^{\circ}$ between the parallel directions (Davies 1978). 

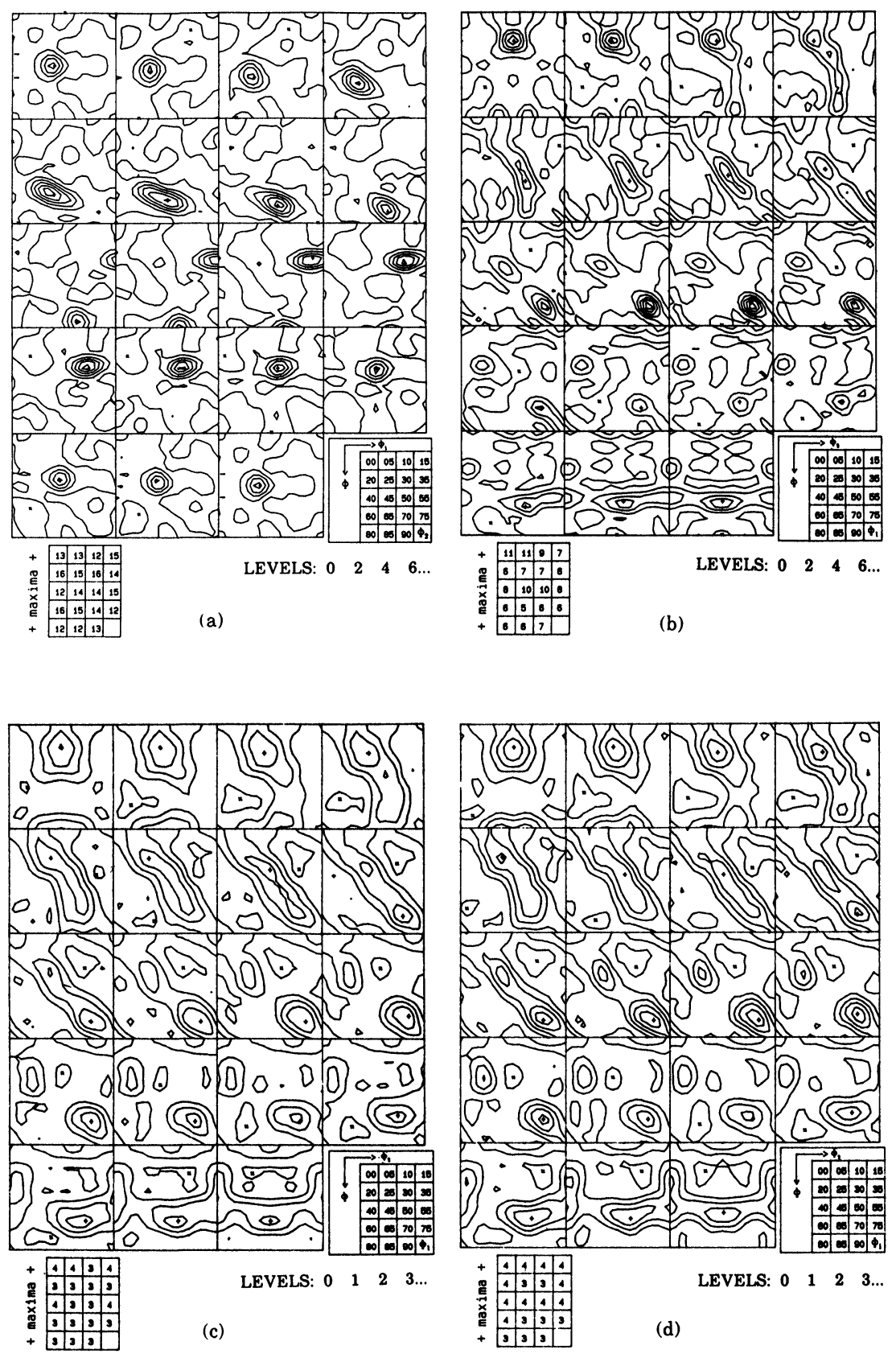

Figure 1 (a) $\Phi_{2}$ sections of the experimental ODF corresponding to the $95 \%$ cold rolled $\mathrm{Ni} 30 \mathrm{Co}$ alloy. (b)-(d) $\Phi_{1}$ sections of the ODF obtained by transforming Figure 1(a) according to the Bain, $\mathrm{K}-\mathrm{S}$ and $\mathrm{N}-\mathrm{W}$ relationships, respectively. 


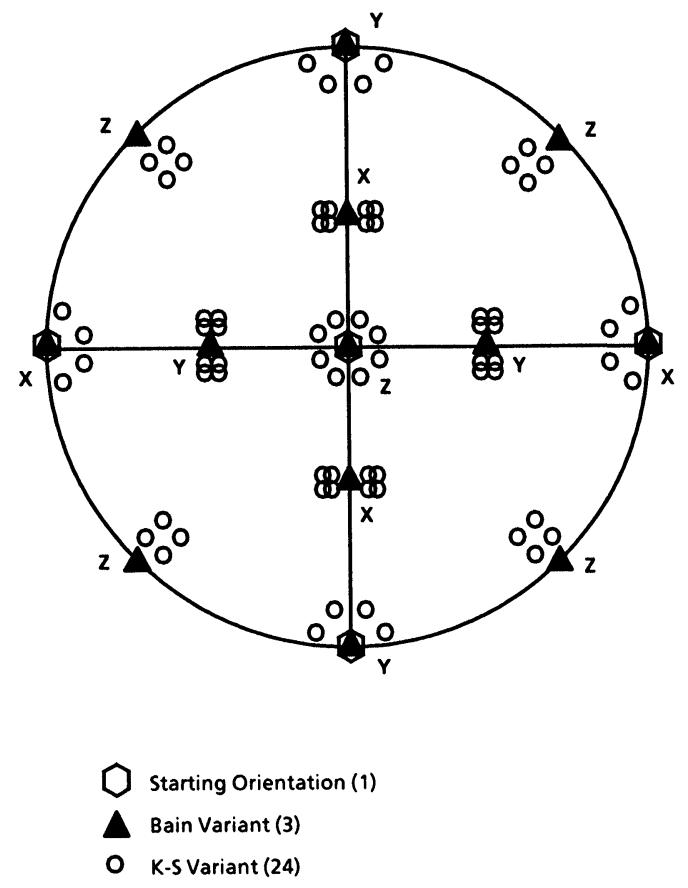

Figure 2 Schematic (001) pole figure of all the variants of the bcc phase formed from a (001) [100] oriented fec crystal following the Bain and K-S relationships (Furubayashi et al., 1987).

Figure 2 shows a schematic (001) pole figure of all the variants of the bcc phase formed from a (001) [100] oriented fcc crystal following the Bain and $\mathrm{K}-\mathrm{S}$ relationships (Furubayashi et al., 1987). It can be seen from this figure that the Bain relation gives rise to a much narrower pole distribution than the $\mathrm{K}-\mathrm{S}$ relation. This is because each Bain variant is surrounded by eight $\mathrm{K}-\mathrm{S}$ variants. Thus the ODF's obtained from the Bain transformation are expected to be sharper than those deduced from the $\mathrm{K}-\mathrm{S}$ or $\mathrm{N}-\mathrm{W}$ relationship.

The $\Phi_{2}$ sections of the experimental ODF pertaining to the cold rolled Ni-40 Co alloy are presented in Figure $3 a$. The $\Phi_{1}$ sections of the ODF produced according to the $\mathrm{K}-\mathrm{S}$ transformation are illustrated in Figure $3 \mathrm{~b}$. The corresponding sections of the experimental and transformed ODF's for the $\mathrm{Ni}-60 \mathrm{Co}$ alloy are shown in Figures $4 \mathrm{a}$ and $4 \mathrm{~b}$. Here only the $\mathrm{K}-\mathrm{S}$ relation is used, as it leads to more realistic results than the Bain criterion (see Discussion below), and is physically better based than the N-W (Inagaki 1984, Inagaki 1988). However, it should be noted that, because of the multiplicity of variants in this transformation, the $\alpha$ textures always appear less intense than the $\gamma$ textures from which they are derived (see also Figure 1).

Whereas the rolling texture of $\mathrm{Ni} 30 \mathrm{Co}\left(\mathrm{SFE} \sim 72 \mathrm{~mJ} / \mathrm{m}^{2}\right.$ ) is expected to be of the pure metal type, and that of $\mathrm{Ni} 60 \mathrm{Co}\left(\mathrm{SFE} \sim 13 \mathrm{~mJ} / \mathrm{m}^{2}\right)$ of the alloy type, that of the cold rolled $\mathrm{Ni} 40 \mathrm{Co}\left(\mathrm{SFE} \sim 52 \mathrm{~mJ} / \mathrm{m}^{2}\right.$ ) should lie between those of the pure metal and the alloy (Ray and Lücke, unpublished research). These 

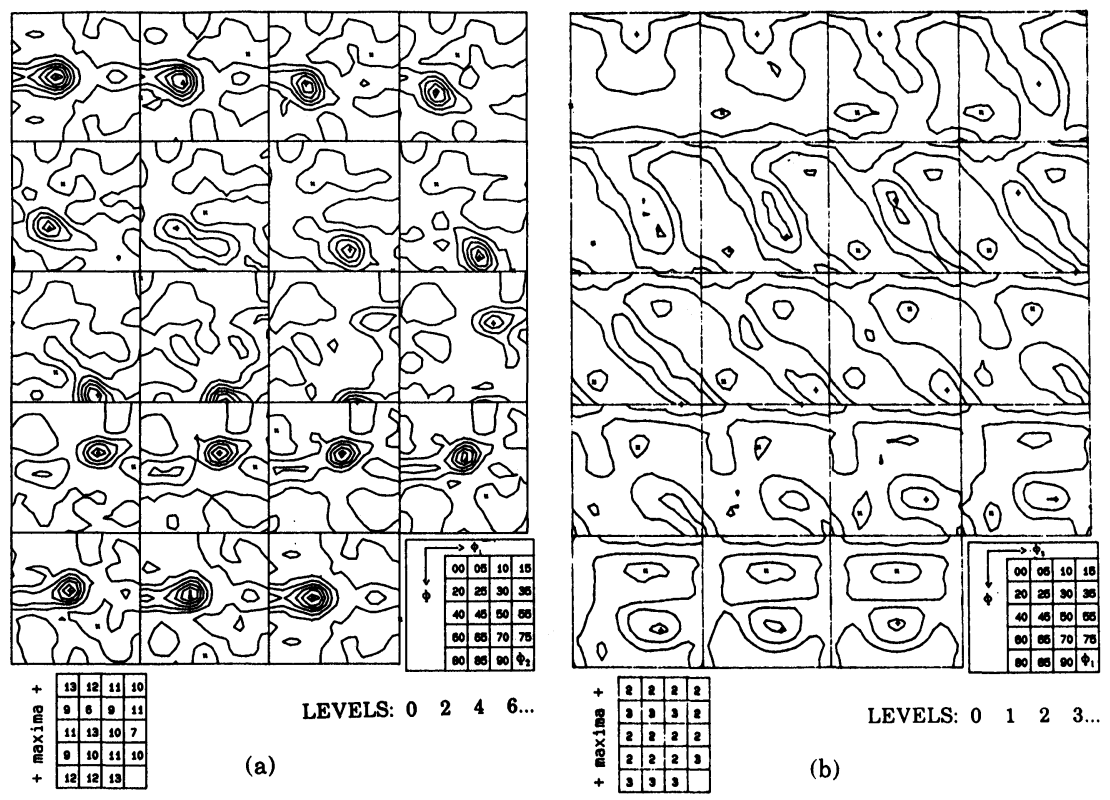

Figure 3 (a) $\Phi_{2}$ sections of the experimental ODF corresponding to the Ni 40 Co alloy. (b) $\Phi_{1}$ sections of the ODF obtained by transforming Figure 3(a) according to the $\mathrm{K}-\mathrm{S}$ relationship.
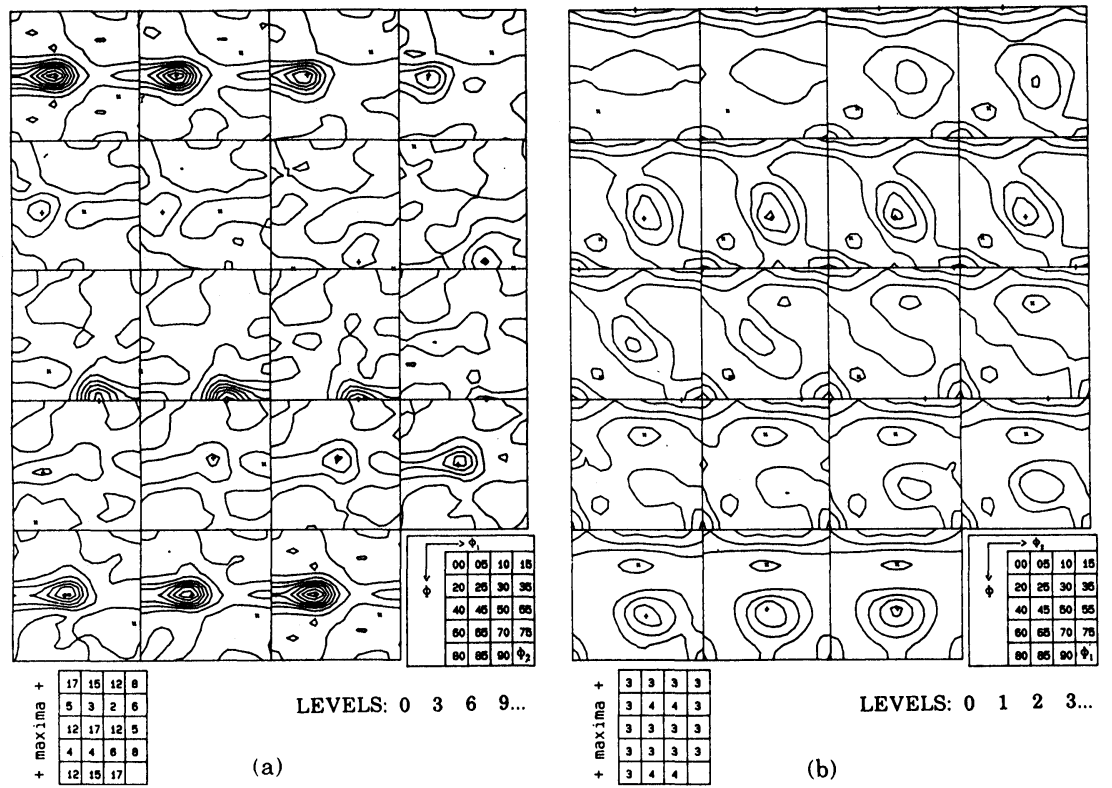

Figure 4 (a) $\Phi_{2}$ sections of the experimental ODF corresponding to the Ni 60 Co alloy. (b) $\Phi_{1}$ sections of the ODF obtained by transforming Figure 4(a) according to the K-S relationship. 
expectations are verified by the ODF's of Figures 1a, 3a and 4a. The above SFE values for the different $\mathrm{Ni}-\mathrm{Co}$ alloys were calculated from the recently reported SFE value for pure Ni and its dependence on Co concentration (Haasen 1978, Beeston and France 1968). Thus, the $\Phi_{1}$ sections of the transformed ODF's shown in Figures 1, 3 and 4 encompass the possible transformation textures that should be obtained from fcc $\gamma$ with a range of SFE values.

\section{DISCUSSION}

The extent of correspondence between the analytically predicted bcc textures and experimental textures determined on HSLA steels will now be considered. For this purpose, the ODF reported by Inagaki (1983) for a controlled rolled $0.10 \mathrm{C}-1.24 \mathrm{Mn}-0.03 \mathrm{Nb}-0.067 \mathrm{~V}$ steel is presented in Figure 5a. (Here the Roe notation and $\Psi$ sections are employed, as in the original publication.) The $\mathrm{Nb}-\mathrm{V}$ steel was hot rolled in the recrystallized $\gamma$ range and then controlled rolled to a total reduction of $\sim 85$ per cent at a finishing temperature of $850^{\circ} \mathrm{C}$. The presence of $\mathrm{Nb}$ and $\mathrm{V}$ ensured that the $\gamma$ rolling texture was retained before transformation into $\alpha$. Moreover, as mentioned above, the SFE's of the fcc Ni $30 \mathrm{Co}$ alloy and the austenite of the experimental steel are expected to be comparable. The ODF's for the Ni30 Co alloy calculated according to the K-S and Bain relationships are illustrated in Figures $5 b$ and $5 c$. Although the general features of the textures represented by all three figures are similar, the intensities in the experimental steel correspond best with those calculated from the $\mathrm{K}-\mathrm{S}$ relationship. The intensity levels in the Bain-related ODF are above 2-2.5 times the respective values for the experimental steel, in agreement with Figure 2. These results support the general view that ferrite transforms from austenite according to the $\mathrm{K}-\mathrm{S}$ relationship, even when the transformation takes place from heavily deformed austenite.

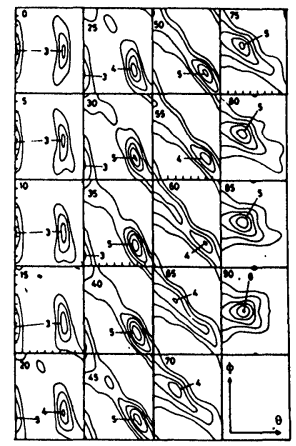

(a)

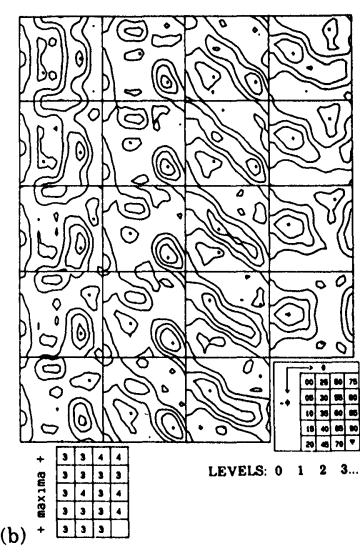

(b)

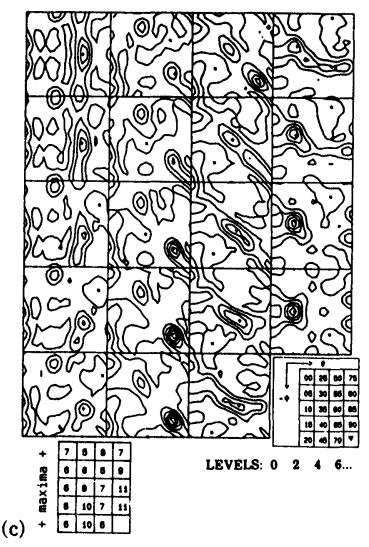

Figure 5 (a) $\Psi$ sections of the experimental ODF for a controlled rolled $\mathrm{Nb}-\mathrm{V}$ steel (Inagaki 1983). (b), (c) $\Psi$ sections of the ODF's obtained by transforming Figure 1(a) according to the $\mathrm{K}-\mathrm{S}$ and Bain relationships, respectively. 
(a)
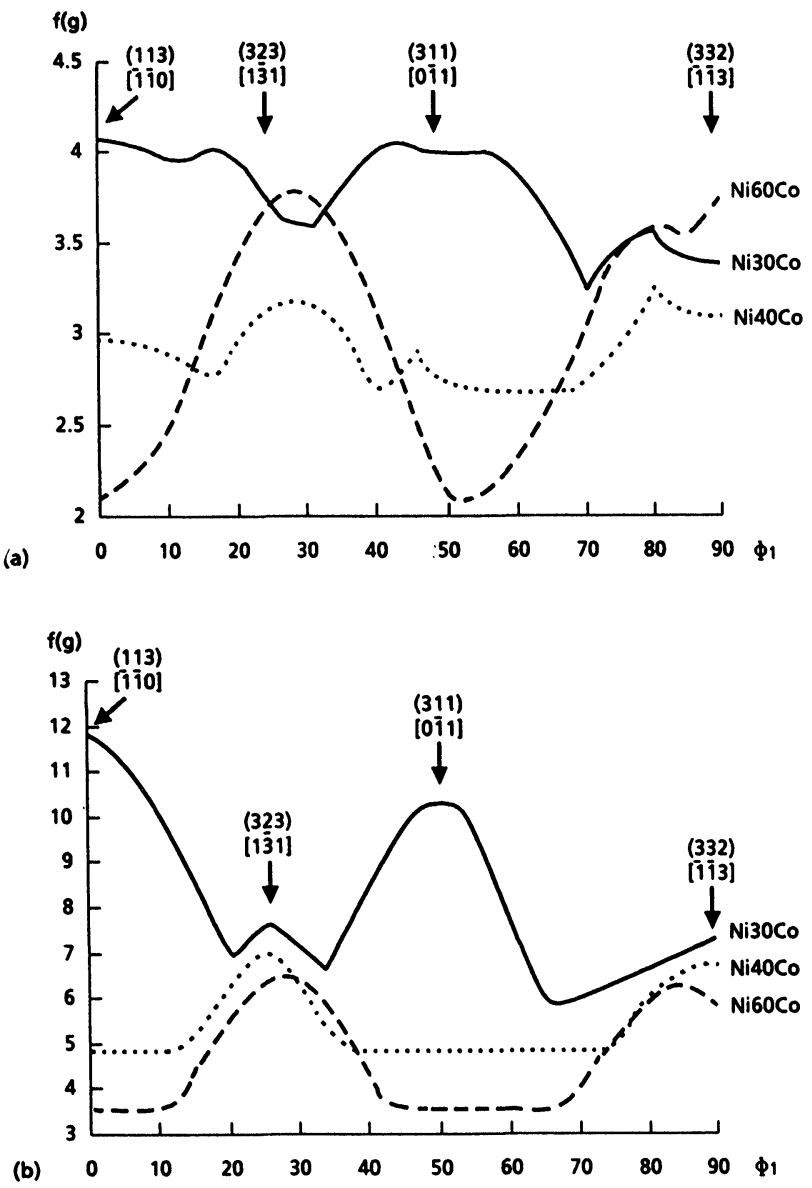

Figure 6 Skeleton lines deduced from the ODF's for the $\mathrm{Ni} 30 \mathrm{Co}$, Ni $40 \mathrm{Co}$ and $\mathrm{Ni} 60 \mathrm{Co}$ alloys transformed according to: (a) the K-S relationship; (b) the Bain relationship.

A close look at the ODF's presented above indicates that the main components of the transformation texture are $\{332\}\langle 113\rangle$ and $\{311\}\langle 011\rangle$. It has been suggested that these orientations originate from the $\{110\}\langle 112\rangle(\mathrm{Bs})$ and $\{112\}\langle 111\rangle(\mathrm{Cu})$ components of the texture in the $\gamma$ phase, respectively (Inagaki, 1977). The skeleton lines deduced from the ODF's for Ni $30 \mathrm{Co}, \mathrm{Ni} 40 \mathrm{Co}$ and $\mathrm{Ni} 60 \mathrm{Co}$ using the K-S and Bain relationships are depicted in Figures $6 \mathrm{a}$ and $6 \mathrm{~b}$, respectively. The essential features of these two sets of lines are similar, although the intensity levels associated with the Bain plots of Figure $6 \mathrm{~b}$ are about 2-3 times those for the K-S plots of Figure 6a, as expected. In these figures, the relative weights of the main ferrite texture components, namely, the $\{332\}\langle 113\rangle$ and $\{311\}\langle 011\rangle$, merit closer study. Thus, while the $\alpha$ texture calculated from the $\gamma$ texture of the Ni 30 Co alloy (high SFE) consists of a sharp $\{311\}\langle 011\rangle$ component and a somewhat less sharp $\{332\}\langle 113\rangle$ component, the $\alpha$ texture 
Table $3 f(g)$ values of cold rolled texture components in the experimental alloys

\begin{tabular}{|c|c|c|c|}
\hline \multirow[t]{2}{*}{ Texture component } & \multicolumn{3}{|l|}{ Alloy } \\
\hline & $\mathrm{Ni} 30 \mathrm{Co}$ & $\mathrm{Ni} 40 \mathrm{Co}$ & $\mathrm{Ni} 60 \mathrm{Co}$ \\
\hline $\begin{array}{l}\{112\}\langle 111\rangle \mathrm{Cu} \\
\{110\}\langle 112\rangle \mathrm{Bs} \\
\{123\}\langle 634\rangle \mathrm{S}\end{array}$ & $\begin{array}{l}14.8 \\
13.7 \\
15.9\end{array}$ & $\begin{array}{r}4.4 \\
13.4 \\
10.7\end{array}$ & $\begin{array}{r}0.0 \\
17.3 \\
4.6\end{array}$ \\
\hline
\end{tabular}

derived from the Ni60 Co alloy (low SFE) displays a sharp $\{332\}\langle 113\rangle$ component and a rather weak $\{311\}\langle 011\rangle$ component. The $\alpha$ texture derived from the Ni 40 Co alloy (medium SFE), is much flatter, with the intensities of the $\{332\}\langle 113\rangle$ and $\{311\}\langle 011\rangle$ components not differing significantly from each other.

The values of the orientation distribution function $f(g)$ for the major rolling components are illustrated in Table 3 for the three experimental alloys. From Figure 6 and Table 3, it is apparent that a high intensity of the $\{332\}\langle 113\rangle$ component in the derived $\alpha$ texture in an alloy is associated with a high intensity of the Bs component, $\{110\}\langle 112\rangle$, in the original rolling texture for that alloy. Similarly, a strong $\{311\}\langle 011\rangle \alpha$ texture component can be linked with the presence of a strong $\mathrm{Cu}$ component, $\{112\}\langle 111\rangle$, in the original texture. Furthermore, the comparable intensities of the $\{332\}\langle 113\rangle$ component in all three experimental alloys can be related to the similarity of the $f(g)$ values of their $\{110\}\langle 112\rangle$ components (Table 3 ). These results lend strong support to the view that the major texture components in ferrite, $\{332\}\langle 113\rangle$ and $\{311\}\langle 011\rangle$, originate from the $\mathrm{Bs}$ and $\mathrm{Cu}$ components, respectively, of the texture of the deformed austenite in a particular steel.

In the literature, there is little mention of the role played by the third most important component of the $\gamma$ rolling texture, namely the $\{123\}\langle 634\rangle$ or $\mathrm{S}$ component. For the present purpose, it was assumed that the $\gamma$ rolling texture consists solely of the $\mathrm{Bs}, \mathrm{Cu}$ and $\mathrm{S}$ components. The orientations obtained by transforming these three components according to the $\mathrm{K}-\mathrm{S}$ relationship are illustrated in Figure 7. For this calculation, all the lattice variants were equally favoured. The ODF obtained by transforming the texture of the cold rolled $\mathrm{Ni} 30 \mathrm{Co}$ alloy using the $\mathrm{K}-\mathrm{S}$ relationship is shown superimposed on the orientations derived from the $\mathrm{Bs}, \mathrm{Cu}$ and $\mathrm{S}$ components in the same figure. The most important feature of this diagram is that the major orientation density maxima in the different $\Phi_{1}$ sections are made up of the transformed Bs, Cu and S orientations. In addition, many of the minor maxima are also accounted for.

One of the twelve orientations formed from the Bs is the $\{332\}\langle 113\rangle$, whereas $\{311\}\langle 011\rangle$ is one of the twelve obtained from the $\mathrm{Cu}$. Three each of the remaining transformed $\mathrm{Bs}$ and $\mathrm{Cu}$ orientations lie within $10^{\circ}-15^{\circ}$ in Euler space from the $\{332\}\langle 113\rangle$ and $\{311\}\langle 011\rangle$ positions. In addition, about two out of twenty four of the transformed $S$ orientations lie close to each of the above two orientations. Thus, transformation of the $\gamma$ rolling texture leads directly to the formation of the $\{332\}\langle 113\rangle$ and $\{311\}\langle 011\rangle$ components in the manner described above. 
LEVELS: $0 \quad 1 \quad 2 \quad 3 \ldots$

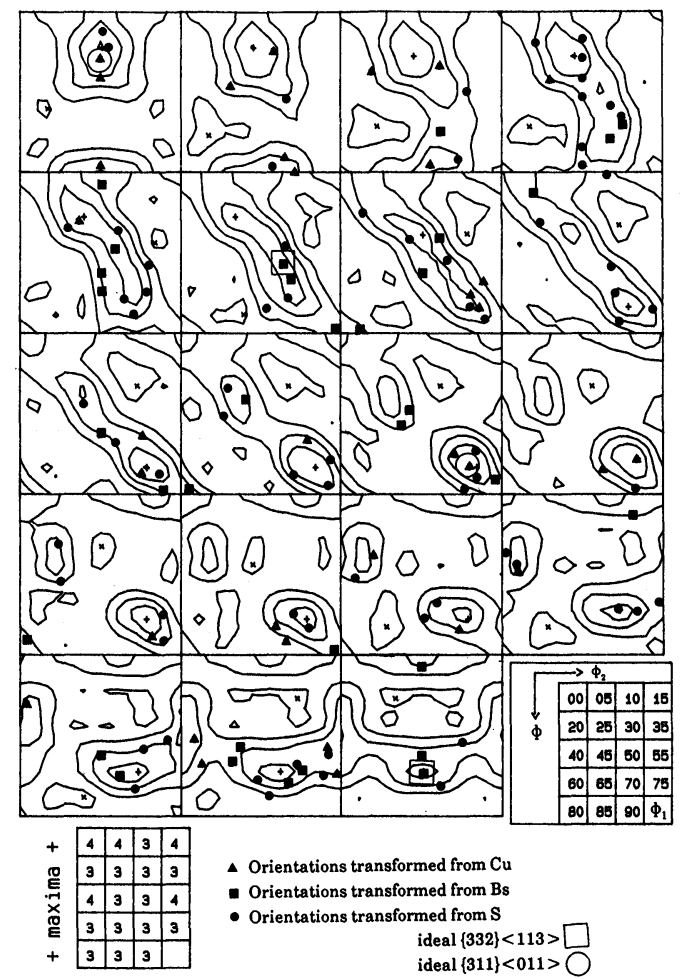

Figure 7 The ODF obtained by transforming the texture of the cold rolled Ni $30 \mathrm{Co}$ alloy is superimposed on the positions corresponding to the ideal $\mathrm{Cu}$, Bs and $\mathrm{S}$ components of the fcc cold rolling texture, both transformed according to the $\mathrm{K}-\mathrm{S}$ relationship.

There is a practical interest in the determination of the origin of the $\{332\}\langle 113\rangle$ and $\{311\}\langle 011\rangle$ components in the transformation texture of steels. $R$ value predictions for these two ideal orientations carried out by the relaxed constraint method (Daniel 1989) are presented in Figure 8. The corresponding values for $\bar{R}$ and $\Delta R$ for the $\{332\}\langle 113\rangle$ component are 2.7 and 1.9 , respectively. By contrast, these two parameters take the values 1.0 and -1.7 for the $\{311\}\langle 011\rangle$ component. Thus the $\{332\}\langle 113\rangle$ leads to an increase in $\mathbf{R}$ value and to the presence of 0 and $90^{\circ}$ ears, whereas the $\{311\}\langle 011\rangle$ leads to a change in the sign of $\Delta R$ and therefore to the presence of $45^{\circ}$ ears. In this way, it is clear that there is a need to control the volume fractions of these two components during processing so as to produce relatively high $\bar{R}$, with minimum $|\Delta R|$.

Finally, an attempt is made here to compare an experimentally determined martensite texture with the analytically predicted $\alpha$ texture for the $\mathrm{Ni} 40 \mathrm{Co}$ alloy. Humbert et al. (1988) rolled sheets of an $\mathrm{Fe} 30 \mathrm{Ni}$ alloy in the austenite phase to a total reduction of 80 per cent before transforming into martensite. The SFE of this alloy is expected to be $\sim 45 \mathrm{~mJ} / \mathrm{m}^{2}$ (Charnock and Nutting 1967), which is not very different from that of the present $\mathrm{Ni} 40$ Co alloy $\left(\sim 52 \mathrm{~mJ} / \mathrm{m}^{2}\right) . \Phi_{2}$ sections of 


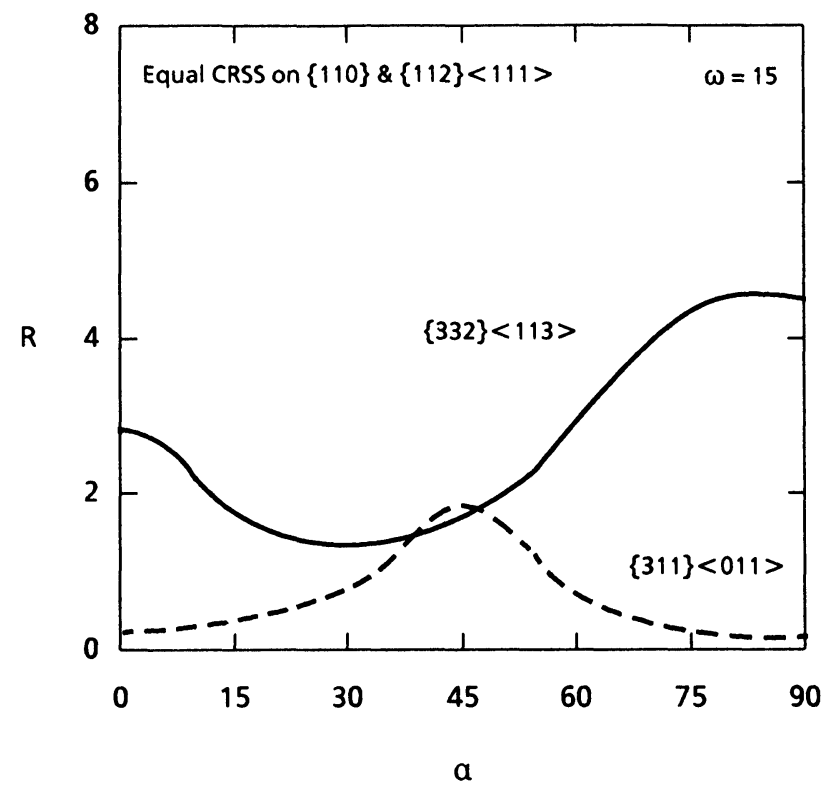

Figure 8 Variation of $\mathrm{R}$ with $\alpha$, the angle to the rolling direction, predicted for the ideal orientations $\{332\}\langle 113\rangle$ and $\{311\}\langle 011\rangle$ by Daniel (1989) using the method of relaxed constraints.

the experimental ODF of Humbert et al. are presented in Figure 9a. Figures $9 b$ and 9c show the $\Phi_{2}$ sections of the ODF's predicted for the Ni 40 Co alloy using the $\mathrm{K}-\mathrm{S}$ and Bain relationships, respectively. No variant selection was assumed during the transformation. It is apparent from Figure 9 that, although the intensity maxima in the experimental and predicted textures appear at about the same locations in orientation space, these are much weaker in the simulated textures than in the experimental one. Furthermore, there are additional peaks in the simulated textures which are not present in the experimental texture. These results indicate that variant selection is likely to take place during martensite formation, in agreement with the conclusions of Humbert et al. (1988) and others (Hu and Kallend, 1981; Bateman and Davies, 1981).

\section{CONCLUSIONS}

1. Transformation textures for steels were estimated by transforming the ODF's for rolled Ni-Co alloys according to the Bain, Kurdjumov-Sachs and Nishiyama-Wassermann relationships. The transformed ODF's obtained from the Bain relation are much sharper than the ODF's deduced from the other two criteria. The ferrite texture determined in a controlled rolled steel heavily deformed in the austenite range agrees best with the $\mathrm{K}-\mathrm{S}$ texture predicted from the rolled Ni-Co alloy with similar stacking fault energy. Such agreement is obtained without any variant selection.

2. The major texture components of the ferrite derived from deformed 
(a)

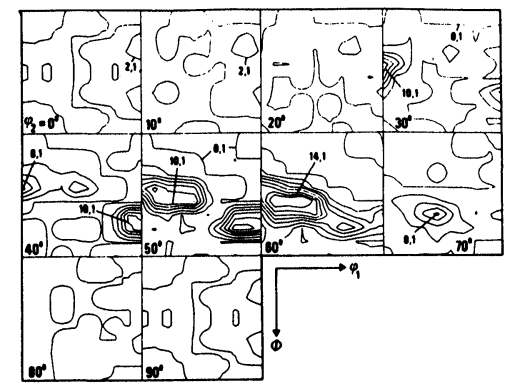

(b)

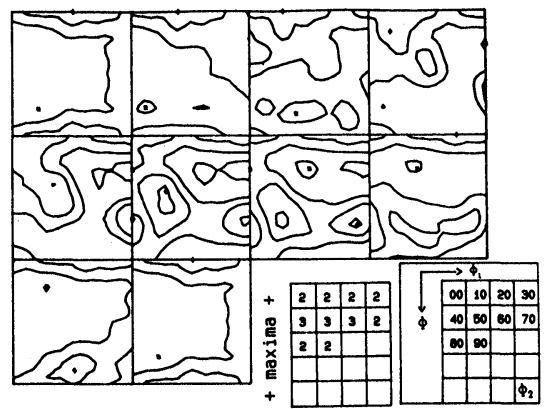

(c)

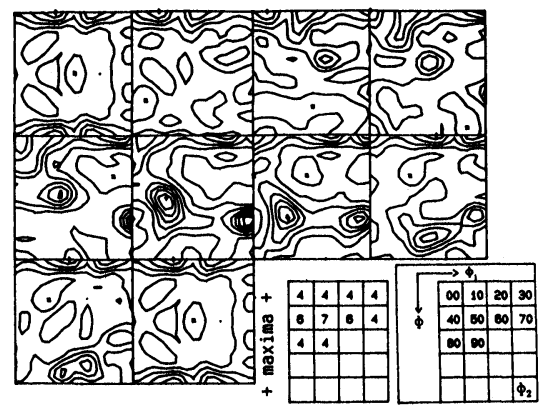

Figure 9 (a) $\Phi_{2}$ sections of the experimental ODF for the martensite formed from an Fe $30 \mathrm{Ni}$ alloy (Humbert et al. 1988). (b), (c) $\Phi_{2}$ sections of the bcc ODF's predicted for the present $\mathrm{Ni} 40$ Co alloy using the $\mathrm{K}-\mathrm{S}$ and Bain relationships, respectively.

austenite are the $\{332\}\langle 113\rangle$ and $\{311\}\langle 011\rangle$; these originate from the $\{110\}\langle 112\rangle(\mathrm{Bs})$ and $\{112\}\langle 111\rangle(\mathrm{Cu})$ orientations, respectively, which are the two major rolling texture components of fcc $\gamma$. Several of the transformed $\mathrm{S}\{123\}\langle 634\rangle$ orientations also lie close to the above ferrite orientations. Of these, the $\{332\}\langle 113\rangle$ component leads to 0 and $90^{\circ}$ ears and to a higher $\overline{\mathbf{R}}$ value than the $\{311\}\langle 011\rangle$ component, which promotes the formation of $45^{\circ}$ ears.

3 . The texture of martensite formed from deformed austenite indicates that variant selection probably plays a role in this kind of transformation. 


\section{ACKNOWLEDGEMENTS}

The authors would like to thank Mr. D. Daniel of the Department of Metallurgical Engineering, McGill University for providing some of his unpublished results. They are also grateful to the Canadian Steel Industry Research Association and the Ministry of Education of Quebec (FCAR program) for financial support. RKR acknowledges with gratitude the receipt of an International Scientific Exchange Award granted by the Natural Sciences and Engineering Research Council of Canada, as well as the period of sabbatical leave accorded by the Indian Institute of Technology, Kanpur, India.

\section{References}

Bain, E. C. (1924). Trans. AIME 70, 25

Bateman, R. M. and Davies, G. J. (1981). Proc. Sixth Int. Conf. on Textures of Materials, The Iron and Steel Inst. of Japan, 690.

Beeston, B. E. P. and France, L. K. J. (1968). Inst. Metals 96, 105.

Bunge, H. J. (1969). Mathematische Methoden der Texturanalyse, Akademie-Verlag, Berlin.

Bunge, H. J., Humbert, M. and Welch, P. I. (1984). Textures and Microstructures 6, 81.

Chapellier, Ph. (1989). M. Eng. Thesis, McGill University.

Charnock, W. and Nutting, J. (1967). Met. Sci. J. 1, 123.

Daniel, D. (1989). Ph.D. Thesis, McGill University.

Davies, G. J. (1978). Proc. Fifth Int. Conf. on Textures of Materials, Springer Verlag, Berlin 1, 121.

Furubayashi, E., Miyaji, H. and Nobuki, M. (1987). Trans. ISIJ 27, 513.

Gallagher, P. C. J. (1970). Metall. Trans. 1, 2429.

Haasen, P. (1978). Physical Metallurgy, Cambridge University Press, 116.

Hu, H. and Kallend, J. S. (1981). Proc. Sixth Int. Conf. on Textures of Materials, The Iron and Steel Inst. of Japan 1, 164.

Humbert, M., Wagner, F., Liu, W. P., Esling, C. and Bunge, H. J. (1988). Proc. Eighth Int. Conf. on Textures of Materials, The Met. Soc. Inc., 743.

Inagaki, H. (1977). Trans. ISIJ 17, 166.

Inagaki, H. (1983). Z. Metallkde. 74, 716.

Inagaki, H. (1984). Z. Metallkde. 75, 510.

Inagaki, H. (1988). Z. Metallkde. 79, 716.

Jura, J. and Pospiech, J. (1978). Textures 3, 1.

Kallend, J. S. and Davies, G. J. (1972). Phil. Mag. 25, 471.

Kurdjumov, G. and Sachs, G. (1930). Z. Physik 64, 325.

Lücke, K. (1981). Proc. Sixth Int. Conf. on Textures of Materials, The Iron and Steel Inst. of Japan, $1,14$.

Nishiyama, Z. (1934). Sci. Rep. Tohoku Univ. I 23, 637.

Ray, R. K. and Lücke, K. unpublished research.

Wassermann, G. (1933). Archiv. für das Eisenhütt. 16, 647. 